\title{
Improvement Of Frontal Lobe Dysfunction And White Matter Integrity By rTMS In Treatment-Resistant Depression
}

This article was published in the following Dove Press journal: Neuropsychiatric Disease and Treatment

\author{
Hiroshi Tateishi ${ }^{1}$ \\ Masashi Nishihara ${ }^{2}$ \\ Atsushi Kawaguchi ${ }^{3}$ \\ Jun Matsushima ${ }^{4}$ \\ Toru Murakawa ${ }^{4}$ \\ Yoshinori Haraguchi ${ }^{4}$ \\ Yutaka Kunitake \\ Toshihiko Maekawa iD ${ }^{5}$ \\ Takahiro A Kato (iD ${ }^{5}$ \\ Toyoko Asami ${ }^{6}$ \\ Yoshito Mizoguchi ${ }^{4}$ \\ Akira Monjii \\ 'Department of Psychiatry, Saga \\ University Hospital, Saga 849-850 I, Japan; \\ ${ }^{2}$ Department of Radiology, Saga \\ University Hospital, Saga 849-850 I, Japan; \\ ${ }^{3}$ Center of Comprehensive Community \\ Medicine, Faculty of Medicine, Saga \\ University, Saga 849-850I, Japan; \\ ${ }^{4}$ Department of Psychiatry, Faculty of \\ Medicine, Saga University, Saga 849-850I, \\ Japan; ${ }^{5}$ Department of Neuropsychiatry, \\ Graduate School of Medical Sciences, \\ Kyushu University, Maidashi Higashi-ku, \\ Fukuoka 842-8582, Japan; ${ }^{6}$ Department \\ of Rehabilitation Medicine, Saga \\ University Hospital, Saga 849-850I, Japan
}

Correspondence: Hiroshi Tateishi Department of Psychiatry, Saga University Hospital, Nabeshima, Saga 849-850I, Japan

Email tateishh@cc.saga-u.ac.jp

Akira Monji

Department of Psychiatry, Faculty of

Medicine, Saga University, Nabeshima,

Saga 849-850I, Japan

Email amonji@hf.rim.or.jp

\begin{abstract}
Aim: The impairment experienced by many individuals with depression is closely related to the cognitive symptoms of the disorder. Repetitive transcranial magnetic stimulation (rTMS) is a noninvasive brain stimulation method providing a promising technique for improving cognitive symptoms in treatment-resistant depression (TRD). In the present study, we investigated whether a relationship exists between improvements in frontal lobe dysfunction induced by rTMS and improvement of white matter integrity revealed by diffusion tensor imaging (DTI) in TRD patients receiving rTMS treatment.
\end{abstract}

Methods: A total of 12 patients with TRD were enrolled in a high-frequency $(10 \mathrm{~Hz})$ rTMS study (August 2013-January 2019). Frontal lobe function and depressive symptoms were assessed at baseline and at the endpoint of rTMS treatment. Fractional anisotropy (FA), as a measure of white matter integrity obtained from DTI, was investigated using a region-ofinterest (ROI) approach.

Results: rTMS treatment significantly improved depressive symptom scores and some subscales of frontal lobe dysfunction. Category scores in the Word Fluency Test and scores on part 3 of the Color Stroop Test were improved independently of the improvement of depressive symptoms. In the ROI analysis, none of the FA increases in any region were correlated with improvement of any frontal lobe function $(n=12)$.

Conclusion: Although rTMS resulted in partial improvement of frontal lobe dysfunction as well as white matter integrity, we found no correlation between improved frontal lobe dysfunction and improved white matter integrity in TRD patients.

Keywords: repetitive transcranial magnetic stimulation, fractional anisotropy, diffusion tensor imaging, treatment-resistant depression, frontal lobe function

\section{Introduction}

Depression is a serious public health problem with a high global prevalence. Major depressive disorder (MDD) has a 12-month prevalence of $6.6 \%$ and a lifetime prevalence of $16.2 \%$, and causes considerable impairment. The impairment experienced by many individuals with depression is closely related to the cognitive symptoms of the disorder. ${ }^{1}$ Etkin et al.'s results indicated that cognitive dysfunction could have negative predictive value for achieving depressive remission. ${ }^{2}$ Thus, for individuals with MDD to achieve full, functional recovery, cognitive dysfunction must be addressed. Cognitive functioning is a complex process that can be broken down into multiple domains, and the domains most relevant to MDD are attention, memory and learning, executive function, and psychomotor processing. ${ }^{1}$ While several neuropsychological 
studies have demonstrated that cognitive deficits are present across a broad range of cognitive domains in depression, executive function deficits associated with frontal lobe dysfunction are also reported to be prominent among depressed patients. ${ }^{3}$ Depression leads to a series of molecular and cellular events which include changes in intracellular signaling, gene expression, neuronal function, and cellular architecture within brain regions that control mood and cognition. ${ }^{1}$ Affected brain regions include the amygdala, prefrontal cortex, hippocampus, thalamus, cingulate cortex, insula, and superior temporal gyrus. ${ }^{1}$ Individuals with depression tend to translate a negative bias in perception, attention, and memory into conscious thoughts, memories, and actions, often showing greater attention and memory to negative stimuli. ${ }^{1}$ Indeed, these emotion-laden functions related to negative affect are sometimes referred to as "hot" cognition, to distinguish them from "cold" cognition, or emotion-independent areas including executive function, information processing speed, learning and memory, and attention/concentration. ${ }^{1}$ One STAR*D study report found that the patients who had not regained normal functioning at remission had a higher depression relapse compared with patients who had recovered normal functioning. ${ }^{1,4}$ Repetitive transcranial magnetic stimulation (rTMS) is a noninvasive brain stimulation technique that is considered a valuable and promising technique for improving cognitive symptoms in treatment-resistant depression (TRD) ${ }^{5,6}$ and traumatic brain injury ${ }^{7}$ Hayasaka et al reported that 10 daily sessions of $20-\mathrm{Hz}$ left prefrontal rTMS in patients with major depression increased the hippocampal volume on the stimulated side, which could potentially be related to the improvement of cognitive function. ${ }^{8}$ Nilakantan et al's study demonstrated that high-frequency transcranial magnetic stimulation selectively modified neural and behavioral hallmarks of age-related memory impairment, indicating effective engagement of memory intervention targets in older adults. ${ }^{9}$ Shinba et al.'s study demonstrated increase of frontal cerebral blood volume during TMS in depression is related to treatment effectiveness using near-infrared spectroscopy. $^{10}$

In addition, previous studies have reported that the major brain regions exhibiting white matter abnormalities in depressive patients include the frontal, temporal and limbic lobes. ${ }^{11-15}$ Diffusion tensor imaging (DTI) with magnetic resonance imaging (MRI) has been widely used to detect white matter microstructural changes. ${ }^{16}$ The measure of fractional anisotropy (FA) obtained with DTI is a scalar measure ranging from 0 to 1 that indicates the degree of anisotropy in diffusion. However, to date, only a few studies have explored the relationship between changes in FA induced by rTMS and treatment responses. ${ }^{17,18}$

To the best of our knowledge, no previous reports have examined the relationship between changes in FA values and changes of frontal lobe function induced by rTMS treatment for TRD. Thus, in the present study, we investigated whether a relationship exists between improvements in frontal lobe dysfunction by rTMS and improvement of white matter integrity revealed by DTI in TRD patients undergoing rTMS treatment.

\section{Methods}

\section{Subjects}

A total of 12 unipolar depression patients (five males and seven females; $52.8 \pm 17.8$ years old) were recruited from the inpatient and outpatient units at the department of psychiatry at Saga University Hospital, fulfilling not only the diagnostic criteria for major depressive episode (DSM-IV-TR), but also the criteria for TRD between August 2013 and January 2019. Treatment resistance was defined as a failure to respond to at least two different types of antidepressant given for a period longer than 4 weeks at the maximum recommended dose. The diagnoses were made by two experienced psychiatrists, and any patients with other psychiatric axis-I or axis-II disorders, history of epileptic seizures or any other neurological disorder, any kind of metal implants, or any other coarse lesions detected with head MRI were excluded. The content of drugs remained unchanged during rTMS treatment. The Beck Depression Inventory (BDI) ${ }^{19}$ and 24-item Hamilton Depressive Rating Scale (HAM-D) ${ }^{20}$ were used to assess clinical symptoms at baseline prior to the first rTMS treatment and at the end of a 6-week treatment period. DTI examination and the Wisconsin Card Sorting Test (WCST), Word Fluency Test (WFT) and Color Stroop Test (CST, $6 \times$ $4=24$ version), psychological examinations for evaluating frontal lobe function, were performed twice at baseline and at the endpoint of treatment. The rater for the HAM-D and cognitive tests was blind to rTMS intervention.

\section{rTMS Treatment}

When the patient was relaxed, a figure-eight-shaped aircooled magnetic coil (Magstim, Magstim rapid system, MR1000/50, The Magstim Company Ltd, Carmarthenshire, UK) was placed over the left dorsolateral prefrontal cortex (DLPFC). The stimulation location was $5 \mathrm{~cm}$ anterior to the 
scalp position for optimum stimulation of the right interosseous dorsalis muscle in the parasagittal plane. ${ }^{21,22}$ All patients were naive to rTMS prior to this study. All patients were treated with active rTMS. All patients and their relatives were given detailed information about the study. A total of 12 patients were treated with active rTMS. The treatment was performed by a skilled rTMS operator. Fitzgerald et al reported that there was an overall significant reduction in the Montgomery-Asberg Depression Rating Scale scores for patients with TRD over a 4-week course of the following parameters: $10 \mathrm{~Hz}, 30$ trains of $5 \mathrm{~s}$ duration, $1500 \mathrm{stimuli} /$ day, 20 session of stimulation at $100 \%$ stimulation intensity (relative to the resting motor threshold; MT). ${ }^{23}$ Hence, according to their study, in the present study the active stimulation was performed according to the following parameters: $10 \mathrm{~Hz}, 40$ trains of $4 \mathrm{~s}$ duration, $1600 \mathrm{stimuli} /$ day, $20 \mathrm{~min}$ per session, 30 sessions of stimulation over a 6-week period, at $100 \%$ stimulation intensity (relative to the resting MT). The center of the figure-eight coil was held flat over the scalp and kept at a $45^{\circ}$ angle with the handle oriented towards the back of the head.

\section{DTI Data Acquisition}

DTI scanning was performed using two clinical 3.0-Tesla MRI units (MAGNETOM Trio, A Tim System, Siemens AG, Erlangen, Germany, $n=3$ or MAGNETOM Skyra, A Tim System, Siemens AG, Erlangen, Germany, n=9) with a 12-channel head coil. The magnetic field intensity was identical in the patient before and after rTMS treatment. Diffusion tensor images were acquired using a spin-echo DTI-echo planar imaging sequence. Twelve-direction DTI scans were acquired with a single shot sequence with the following parameters: relaxation time $(\mathrm{TR})=4600$ to 5800 $\mathrm{ms}$, excitation time $(\mathrm{TE})=68$ to $92 \mathrm{~ms}$, flip angle (degrees) 90, slice thickness $4 \mathrm{~mm}, 35$ to 40 axial slices, acquisition matrix $128 \times 128$, b-value of $1000 \mathrm{sec} / \mathrm{mm}^{2}$ As soon as the subject was enrolled, the demographic data were collected and related scales were measured. The first DTI scan was then performed as a baseline measure (within $24 \mathrm{~h}-1$ month before the first rTMS treatment). The second DTI scan of patients was performed at the endpoint (after 6 weeks of rTMS treatment, within 24-72 $\mathrm{h}$ after the last rTMS session).

\section{Region Of Interest (ROI) Determination}

Oval regions of interest (ROIs) of identical size $\left(20 \mathrm{~mm}^{2}\right)$ were used to measure FA values. The same ROI was used for both measures, and all ROIs were placed on axial

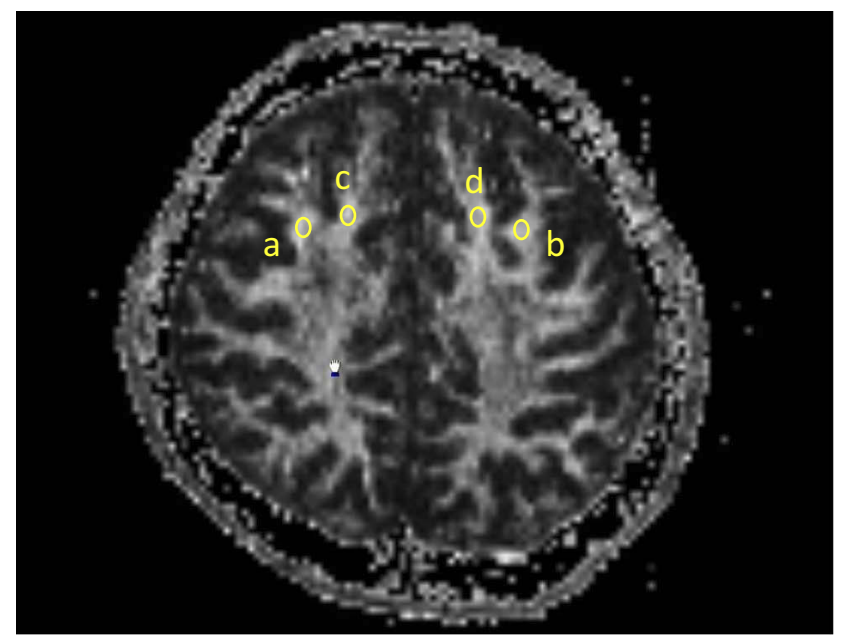

Figure I Oval regions of interest (ROIs) of identical size $\left(20 \mathrm{~mm}^{2}\right)$ were used to measure fractional anisotropy (FA) values. The same ROI was used for both measures, and all ROls were placed on axial slices. Bilateral superior gyri and middle frontal gyri ROls were placed halfway between the precentral sulcus and anterior boundary of the brain, on the most inferior slice where both gyri were visible as separate structures. a: the right middle frontal gyrus, b: the left middle frontal gyrus, c: the right superior frontal gyrus, d: the left superior frontal gyrus.

slices. Bilateral superior gyri and middle frontal gyri ROIs were placed halfway between the precentral sulcus and anterior boundary of the brain, on the most inferior slice where both gyri were visible as separate structures. The researcher who drew the ROIs was blind to the subjects' clinical measurements. We measured the average FA values in each ROI (Figure 1).

\section{Statistical Analysis}

Paired t-tests were conducted to analyze the pre- and posttreatment difference on HAM-D, BDI and frontal lobe function scores.

DTI analysis was performed with an ROI approach.

For the ROI approach, a one-sample paired $t$-test was used for data analysis between pre- and post-treatment. Correlation analysis was applied to evaluate the relationship between the average FA values and depressive scores with Bonferroni correction. These analyses were implemented using IBM SPSS Statistics (SPSS Inc., Chicago, Illinois, USA, Version 18.0).

\section{Results}

\section{Participant Characteristics}

A total of 12 participants completed the study. All participants voluntarily agreed to take part in the present study. The age range was 28 to 74 years, with an average age of 52.8 years $(\mathrm{SD}=17.8$ years). All participants were Japanese. Four of 12 subjects were rTMS-responders 
Table I Participant Characteristics $(\mathrm{N}=12)$

\begin{tabular}{|l|l|}
\hline Age, M (SD) (years) & 52.8 (17.8) \\
Gender (Male/Female) (n) & $5 / 7$ \\
Onset age, M (SD) (year) & $46.9(19.6)$ \\
Last duration of illness, M (SD) (year) & $4.0(4.7)$ \\
Number of episodes, M (SD) & $1.3(0.6)$ \\
Number of antidepressant, M (SD) & $2.9(1.2)$ \\
\hline
\end{tabular}

Abbreviations: $M$, mean; SD, standard deviation.

(responder: reduction of $50 \%$ from baseline HAM-D scores). All subjects had MRI scans conducted before and after rTMS treatments. Participants' characteristics by group are reported in Table 1.

\section{Changes In Depressive Symptoms And Frontal Lobe Function Induced By rTMS}

The mean HAM-D score before rTMS was $20.3 \pm 6.9$ $(\mathrm{n}=12)$ and the mean BDI score was $26.3 \pm 10.7$ $(\mathrm{n}=12)$. The corresponding scores after rTMS were 13.2 \pm 9.0 and $19.5 \pm 12.0$, respectively. Paired $t$-tests analyzing the pre- and post-treatment difference revealed significant decreases in HAM-D and BDI scores $(p=0.0004$ and $p=0.03$, respectively) (Table 2 ).

rTMS treatment significantly improved Category scores in WFT $(p=0.04, \mathrm{n}=12)$ and part 3 of CST scores $(p=0.04, \mathrm{n}=12)$. In rTMS-responders $(\mathrm{n}=4)$ or rTMSnon-responders $(n=8)$, rTMS treatment did not significantly improve any frontal lobe function (Table 2).

\section{Changes In FA Values Induced By rTMS ROI Approach}

The ROI approach $(\mathrm{n}=12)$ revealed that white matter FA in the right superior frontal gyri was significantly increased by rTMS $(p=0.004)$. In rTMS-responders $(n=4)$, the ROI approach did not reveal significantly increased white matter FA in the left and right middle and superior frontal gyri by rTMS. In rTMS-non-responders $(n=8)$, the ROI approach revealed that rTMS significantly increased white matter FA in the right superior frontal gyrus (Table 3).

\section{Correlation Between Changes In FA Values And Frontal Lobe Function As Well As Changes In FA Values And Depressive Symptoms}

In the ROI approach, none of the FA increases in any region were correlated with increases in HAM-D, BDI scores or the improvement of any frontal lobe function $(n=12)$ (Table 4$)$. The amount of changes in FA values and frontal lobe function was calculated by post-pre comparison.

\section{Discussion}

Paired $t$-tests analyzing the pre- and post-treatment difference revealed significant decreases in HAM-D and BDI scores ( $p=0.0004$ and $p=0.03$, respectively) (Table 2 ). rTMS treatment significantly improved Category scores in WFT ( $p=0.04, \mathrm{n}=12)$ and part 3 of CST scores $(p=0.04$, $\mathrm{n}=12)$. In rTMS-responders $(\mathrm{n}=4)$ or rTMS-non-responders $(\mathrm{n}=8)$, rTMS treatment did not significantly improve any frontal lobe function (Table 2). The ROI approach $(n=12)$ revealed that white matter FA in the right superior frontal gyri was significantly increased by rTMS $(p=0.004)$. In rTMS-responders $(\mathrm{n}=4)$, the ROI approach did not reveal significantly increased white matter FA in any region by rTMS. In rTMS-non-responders $(\mathrm{n}=8)$, the ROI approach revealed that rTMS significantly increased white matter FA in the right superior frontal gyrus (Table 3 ). In the ROI approach, none of the FA increases in any region were correlated with increases in HAM-D, BDI scores or the improvement of any frontal lobe function $(\mathrm{n}=12)$ (Table 4$)$.

Previous systematic reviews reported that rTMS can induce significant cognitive improvement. ${ }^{24,25}$ Fitzgerald et al demonstrated significant overall improvements in verbal fluency, independently of the type (high frequency/low frequency) of rTMS received. ${ }^{26}$ Boggio et al reported trends towards improvement in WCST and CST scores in patients with depression and Parkinson's disease. $^{27}$ The DLPFC is a crucial brain region for neurocognitive performance (including attention, memory, executive functions, psychomotor speed and social cognition), and is neuroanatomically connected to fronto-subcortical brain areas, the dysfunctions of which are heavily involved in many neuropsychiatric diseases. ${ }^{28}$ Pallanti et al reported that low-frequency rTMS over right DLPFC in the treatment of TRD improved performance in the Corsi test $(p<0.02)$ and phonemic verbal fluency ( $p=0.065)$, both of which can be used to detect right hemisphere cognitive dysfunction. ${ }^{29}$ These improvements were independent of depressive symptom variation. In the present study, rTMS treatment significantly improved depression symptoms and Category scores in WFT and part 3 of CST scores of frontal lobe dysfunction. These measures improved independently of the improvement of depressive symptoms. 
Table 2 Changes In Depressive Symptoms And Frontal Lobe Function Induced By rTMS

\begin{tabular}{|c|c|c|c|c|c|c|c|}
\hline & \multirow[t]{2}{*}{$\mathbf{n}$} & \multicolumn{2}{|l|}{ Pre } & \multicolumn{2}{|l|}{ Post } & \multirow[t]{2}{*}{$\mathbf{t}$} & \multirow[t]{2}{*}{$p$} \\
\hline & & Mean & SD & Mean & SD & & \\
\hline HAMD & 12 & 20.33 & 6.87 & 13.17 & 8.98 & -5.00 & 0.00 \\
\hline $\mathrm{BDI}$ & 12 & 26.33 & 10.73 & 19.50 & 11.97 & -2.44 & 0.03 \\
\hline WCST CA & 12 & 4.58 & 2.11 & 4.33 & 2.35 & -0.67 & 0.52 \\
\hline $\mathrm{TE}$ & 12 & $|4.4|$ & 4.76 & 14.00 & 7.37 & -0.35 & 0.74 \\
\hline PEN & 12 & 1.67 & 1.61 & 1.67 & 3.08 & 0.00 & 1.00 \\
\hline DMS & 12 & 1.17 & 1.95 & 1.58 & 2.23 & 0.86 & 0.41 \\
\hline WFT phoneme & 12 & 25.25 & 7.21 & 25.58 & 7.83 & 0.35 & 0.73 \\
\hline Category & 12 & 36.25 & 7.20 & 39.42 & 6.47 & 2.40 & 0.04 \\
\hline CST partI & 12 & 16.47 & 5.46 & 14.54 & 1.45 & -1.40 & 0.19 \\
\hline Part2 & 12 & 21.67 & 6.40 & 19.40 & 3.29 & -1.55 & 0.15 \\
\hline Part3 & 12 & 29.00 & 7.65 & 25.76 & 5.28 & -2.34 & 0.04 \\
\hline \multicolumn{8}{|l|}{ Responders } \\
\hline & \multirow[t]{2}{*}{$\mathbf{n}$} & \multicolumn{2}{|l|}{ Pre } & \multicolumn{2}{|l|}{ Post } & \multirow[t]{2}{*}{$\mathbf{t}$} & \multirow[t]{2}{*}{$\mathbf{p}$} \\
\hline & & Mean & SD & Mean & SD & & \\
\hline WCST CA & 4 & 3.00 & 2.94 & 3.00 & 2.58 & 0.00 & 1.00 \\
\hline $\mathrm{TE}$ & 4 & 18.75 & 5.38 & 18.25 & 7.50 & -0.32 & 0.77 \\
\hline PEN & 4 & 3.00 & 2.16 & 3.75 & 4.35 & 0.48 & 0.66 \\
\hline DMS & 4 & 2.50 & 3.00 & 2.50 & 2.65 & 0.00 & 1.00 \\
\hline WFT phoneme & 4 & 23.00 & 7.12 & 21.25 & 5.19 & -0.78 & 0.49 \\
\hline Category & 4 & 35.00 & 4.24 & 36.50 & 5.32 & 1.19 & 0.32 \\
\hline CST part I & 4 & 20.20 & 8.74 & 15.01 & 1.50 & -1.37 & 0.27 \\
\hline Part2 & 4 & 26.33 & 9.32 & $20.7 \mid$ & 1.92 & -1.48 & 0.23 \\
\hline Part3 & 4 & 33.14 & 8.11 & 27.07 & 2.32 & -1.68 & 0.19 \\
\hline \multicolumn{8}{|c|}{ Non-responders } \\
\hline & \multirow[t]{2}{*}{$\mathbf{n}$} & \multicolumn{2}{|l|}{ Pre } & \multicolumn{2}{|l|}{ Post } & \multirow[t]{2}{*}{$\mathbf{t}$} & \multirow[t]{2}{*}{$\mathbf{p}$} \\
\hline & & Mean & SD & Mean & SD & & \\
\hline WCST CA & 8 & 5.38 & 1.06 & 5.00 & 2.07 & $-0.8 \mathrm{I}$ & 0.44 \\
\hline $\mathrm{TE}$ & 8 & 12.25 & 2.66 & 11.88 & 6.77 & -0.22 & 0.83 \\
\hline PEN & 8 & 1.00 & 0.76 & 0.63 & 1.77 & -0.55 & 0.60 \\
\hline DMS & 8 & 0.50 & 0.76 & 1.13 & 2.03 & 1.17 & 0.28 \\
\hline WFT phoneme & 8 & 26.38 & 7.46 & 27.75 & 8.29 & 1.82 & 0.11 \\
\hline Category & 8 & 36.88 & 8.51 & 40.88 & 6.81 & 2.15 & 0.07 \\
\hline CST part I & 8 & $|4.6|$ & 1.46 & 14.30 & 1.46 & -0.59 & 0.57 \\
\hline Part2 & 8 & 19.33 & 2.91 & 18.75 & 3.73 & -0.67 & 0.52 \\
\hline Part3 & 8 & 26.93 & 7.00 & 25.10 & 6.33 & -1.95 & 0.09 \\
\hline
\end{tabular}

Notes: Paired $t$-tests analyzing the pre- and post-treatment difference revealed significant decreases in HAM-D and BDI scores $(p=0.0004$ and $p=0.03$, respectively). $r T M S$ treatment significantly improved Category scores in the word fluency test (WFT) $(p=0.04, n=12)$ and part 3 of the color Stroop test (CST) scores $(p=0.04, n=12)$. In rTMS-responders $(n=4)$ or rTMS-non-responders $(n=8)$, rTMS treatment did not significantly improve any frontal lobe function.

Abbreviations: HAM-D, Hamilton Depressive Rating Scale; BDI, Beck Depression Inventory; WCST, Wisconsin Card Sorting Test; CA, categories achieved; TE, total errors; PEN, the Perseverative Errors of Nelson; DMS, Difficulties of Maintaining Set; WFT, Word Fluency Test; CST, Color Stroop Test.

To date, only a few studies have explored the relationship between the white matter microstructure changes induced by rTMS and treatment responses. ${ }^{17,18}$ In Kozel et al.'s study, four TRD patients treated with active stimulation were compared with four matched patients with sham stimulation. ${ }^{17}$ They concluded that rTMS resulted in no damage to white matter on the side of stimulation. Peng et al reported significantly reduced FA 
Table 3 Changes In FA Values Induced By rTMS

\begin{tabular}{|c|c|c|c|c|c|c|c|}
\hline & \multirow[t]{2}{*}{$\mathbf{n}$} & \multicolumn{2}{|l|}{ Pre } & \multicolumn{2}{|l|}{ Post } & \multirow[t]{2}{*}{$\mathbf{t}$} & \multirow[t]{2}{*}{$p$} \\
\hline & & Mean & SD & Mean & SD & & \\
\hline FA in the left middle frontal gyrus & 12 & 0.588 & 0.094 & 0.581 & 0.080 & -0.563 & 0.585 \\
\hline In the right middle frontal gyrus & 12 & 0.558 & 0.081 & 0.588 & 0.061 & 1.427 & 0.18 \\
\hline In the left superior frontal gyrus & 12 & 0.616 & 0.062 & 0.606 & 0.055 & -0.871 & 0.403 \\
\hline In the right superior frontal gyrus & 12 & 0.562 & 0.070 & 0.587 & 0.072 & 3.512 & 0.005 \\
\hline \multicolumn{8}{|l|}{ Responders } \\
\hline & \multirow[t]{2}{*}{$\mathbf{n}$} & \multicolumn{2}{|l|}{ Pre } & \multicolumn{2}{|l|}{ Post } & \multirow[t]{2}{*}{$\mathbf{t}$} & \multirow[t]{2}{*}{$\mathbf{p}$} \\
\hline & & Mean & SD & Mean & SD & & \\
\hline FA in the left middle frontal gyrus & 4 & 0.532 & 0.090 & 0.546 & 0.073 & 0.486 & 0.660 \\
\hline In the right middle frontal gyrus & 4 & 0.551 & 0.084 & 0.576 & 0.064 & 0.439 & 0.690 \\
\hline In the left superior frontal gyrus & 4 & 0.608 & 0.086 & 0.587 & 0.069 & -1.478 & 0.236 \\
\hline In the right superior frontal gyrus & 4 & 0.513 & 0.100 & 0.533 & 0.094 & 1.035 & 0.377 \\
\hline \multicolumn{8}{|l|}{ Non-responders } \\
\hline & \multirow[t]{2}{*}{$\mathbf{n}$} & \multicolumn{2}{|l|}{ Pre } & \multicolumn{2}{|l|}{ Post } & \multirow[t]{2}{*}{$\mathbf{t}$} & \multirow[t]{2}{*}{$\mathbf{p}$} \\
\hline & & Mean & SD & Mean & SD & & \\
\hline FA in the left middle frontal gyrus & 8 & 0.616 & 0.089 & 0.599 & 0.081 & -1.449 & 0.19 \\
\hline In the right middle frontal gyrus & 8 & 0.562 & 0.085 & 0.594 & 0.063 & 1.829 & 0.110 \\
\hline In the left superior frontal gyrus & 8 & 0.620 & 0.052 & 0.615 & 0.049 & -0.297 & 0.775 \\
\hline In the right superior frontal gyrus & 8 & 0.587 & 0.037 & 0.615 & 0.042 & 4.328 & 0.003 \\
\hline
\end{tabular}

Notes: The region of interest $(\mathrm{ROI})$ approach $(n=12)$ revealed that white matter fractional anisotropy $(\mathrm{FA})$ in the right superior frontal gyri was significantly increased by $r$ TMS $(p=0.004)$. In rTMS-responders $(n=4)$, the ROI approach did not reveal significantly increased white matter FA in any region by rTMS. In $r$ TMS-non-responders $(n=8)$, the $\mathrm{ROI}$ approach revealed that $\mathrm{rTMS}$ significantly increased white matter FA in the right superior frontal gyrus.

Abbreviation: FA, fractional anisotropy.

Table 4 Correlation Between Changes In FA Values And Frontal Lobe Function As Well As Changes In FA Values And Depressive Symptoms $(\mathrm{N}=12)$

\begin{tabular}{|c|c|c|c|c|c|c|c|c|c|c|c|c|}
\hline & & \multirow[t]{2}{*}{ HAM-D } & \multirow[t]{2}{*}{ BDI } & \multicolumn{4}{|c|}{ WCST } & \multicolumn{2}{|l|}{ WFT } & \multicolumn{3}{|l|}{ CST } \\
\hline & & & & CA & TE & PEN & DMS & Phoneme & Category & Partl & Part2 & Part3 \\
\hline $\begin{array}{l}\text { FA in the left } \\
\text { middle frontal } \\
\text { gyrus }\end{array}$ & $\begin{array}{l}\text { Pearson's } \\
\text { correlation } \\
p\end{array}$ & $\begin{array}{l}-0.451 \\
0.141\end{array}$ & $\begin{array}{l}-0.204 \\
0.524\end{array}$ & $\begin{array}{l}0.030 \\
0.926\end{array}$ & $\begin{array}{l}0.391 \\
0.209\end{array}$ & 0.123 & $\begin{array}{l}0.012 \\
0.971\end{array}$ & $\begin{array}{l}-0.757 \\
0.004\end{array}$ & $\begin{array}{l}-0.290 \\
0.360\end{array}$ & $\begin{array}{l}-0.658 \\
0.020\end{array}$ & $\begin{array}{l}-0.715 \\
0.009\end{array}$ & $\begin{array}{l}-0.668 \\
0.018\end{array}$ \\
\hline $\begin{array}{l}\text { FA in the } \\
\text { right middle } \\
\text { frontal gyrus }\end{array}$ & $\begin{array}{l}\text { Pearson's } \\
\text { correlation } \\
p\end{array}$ & $\begin{array}{l}0.154 \\
0.633\end{array}$ & $\begin{array}{l}0.151 \\
0.639\end{array}$ & $\begin{array}{l}0.191 \\
0.552\end{array}$ & $\begin{array}{l}0.081 \\
0.803\end{array}$ & 0.722 & $\begin{array}{l}-0.328 \\
0.298\end{array}$ & $\begin{array}{l}-0.698 \\
0.012\end{array}$ & $\begin{array}{l}-0.154 \\
0.632\end{array}$ & $\begin{array}{l}-0.629 \\
0.028\end{array}$ & $\begin{array}{l}-0.516 \\
0.086\end{array}$ & $\begin{array}{l}-0.679 \\
0.015\end{array}$ \\
\hline $\begin{array}{l}\text { FA in the left } \\
\text { superior } \\
\text { frontal gyrus }\end{array}$ & $\begin{array}{l}\text { Pearson's } \\
\text { correlation } \\
p\end{array}$ & $\begin{array}{l}-0.005 \\
0.988\end{array}$ & $\begin{array}{l}0.183 \\
0.570\end{array}$ & $\begin{array}{l}-0.021 \\
0.949\end{array}$ & $\begin{array}{l}0.226 \\
0.481\end{array}$ & $\begin{array}{l}0.405 \\
0.192\end{array}$ & $\begin{array}{l}0.067 \\
0.837\end{array}$ & $\begin{array}{l}0.000 \\
0.999\end{array}$ & $\begin{array}{l}-0.320 \\
0.310\end{array}$ & $\begin{array}{l}0.167 \\
0.605\end{array}$ & $\begin{array}{l}-0.039 \\
0.905\end{array}$ & $\begin{array}{l}0.182 \\
0.571\end{array}$ \\
\hline $\begin{array}{l}\text { FA in the } \\
\text { right superior } \\
\text { frontal gyrus }\end{array}$ & $\begin{array}{l}\text { Pearson's } \\
\text { correlation } \\
p\end{array}$ & $\begin{array}{l}-0.265 \\
0.405\end{array}$ & $\begin{array}{l}-0.201 \\
0.532\end{array}$ & 0.533 & 0.939 & 0.126 & $\begin{array}{l}-0.548 \\
0.065\end{array}$ & -0.138 & -0.146 & $\begin{array}{l}-0.403 \\
0.194\end{array}$ & $\begin{array}{l}-0.538 \\
0.071\end{array}$ & $\begin{array}{l}-0.232 \\
0.468\end{array}$ \\
\hline
\end{tabular}

Notes: In the region of interest (ROI) analysis, none of the fractional anisotropy (FA) increases in any region were correlated with increases in HAM-D scores, BDI scores, or the improvement of any frontal lobe function $(n=12)$. The amount of changes in FA values and frontal lobe function was calculated by post-pre comparisons. Abbreviations: HAMD, Hamilton Depressive Rating Scale; BDI, Beck Depression Inventory; WCST, Wisconsin Card Sorting Test; CA, categories achieved; TE, total errors; PEN, the Perseverative Errors of Nelson; DMS, Difficulties of Maintaining Set; WFT, Word Fluency Test; CST, Color Stroop Test; FA, fractional anisotropy. 
using a voxel-based analysis method in the left middle frontal gyrus in TRD patients. ${ }^{18}$ This reduction of FA was significantly improved by active rTMS treatment, but not by sham stimulation.

To the best of our knowledge, only a few studies reported an association between white matter FA with cognitive function in MDD using DTI analysis. ${ }^{30,31}$ Alves et al reported that FA in the right posterior cingulate cluster (PCC) (but not left PCC) was significantly positively correlated with performance in a verbal naming task, and showed a non-significant trend towards a correlation with verbal fluency and episodic memory performance. ${ }^{30}$ Rizk et al found that structural connectivity of the white matter network of the caudal anterior cingulate cortex was correlated with the magnitude of Stroop interference in healthy volunteers, but not in MDD patients. ${ }^{31}$

To the best of our knowledge, no previous reports have examined the relationship between changes in FA values and changes of frontal lobe function induced by rTMS treatment for TRD. The present study revealed that none of the FA increases in any region were correlated with the improvement of any frontal lobe function $(n=12)$. Stämpfli et al.'s study suggested that a new fiber density (FD) measure may be more sensitive to subtle changes in white matter microstructure compared with FA in schizophrenia. ${ }^{32}$ Therefore, it may be useful for future studies to use FD instead of FA, to examine this issue in more depth.

\section{Limitations}

The main limitation of the present study was the lack of a control condition using a sham rTMS procedure. In addition, our sample size was relatively small. It has to be pointed out the possibility that we might be able to get some positive correlation by increasing the number of the subjects. The negative correlation might be caused only by this small sample size. It may be useful for future replication studies to confirm the present findings in more depth, using a larger patient sample and including a sham rTMS procedure. The learning effect on the cognitive tests appeared to be robust, because the tests were repeated in relatively short periods (6 weeks), despite the lack of a control group. We did not conduct structured clinical interviews, such as the Structured Clinical Interview for DSMIV-TR or the Mini International Neuropsychiatric Interview. DTI scanning was performed using two clinical 3.0-Tesla MRI units (MAGNETOM Trio or MAGNETOM Skyra).

\section{Conclusion}

To our knowledge, this is the first study to investigate the relationship between rTMS-induced improvements of frontal lobe dysfunction and white matter integrity in TRD patients. The present results suggest that rTMS is effective for treating TRD, and that it is associated with significant improvements on several subscales of frontal lobe dysfunction. Category scores in WFT and part 3 of the CST scores improved independently of the improvement of depressive symptoms. Importantly, we found no correlation between the improvement of frontal lobe dysfunction by rTMS and the improvement of white matter integrity by rTMS in TRD patients.

\section{Statement Of Ethics}

Before enrollment, all subjects were fully informed about the study and gave written informed consent before taking part. The experimental protocols were carried out in accordance with the Declaration of Helsinki and were approved by the Saga University Hospital ethics committee. The registration ID of the clinical trial was 2012-05-02.

\section{Acknowledgment}

Dr. Tateishi was supported by the Japan Society for the Promotion of Science (JSPS KAKENHI Grant Number 17K10307).

\section{Author Contributions}

All authors contributed to data analysis, drafting and revising the article, gave final approval of the version to be published, and agree to be accountable for all aspects of the work.

\section{Disclosure}

The authors report no conflicts of interest in this work.

\section{References}

1. Culpepper L, Lam RW, McIntyre RS. Cognitive impairment in patients with depression: awareness, assessment, and management. J Clin Psychiatry. 2017;78(9):1383-1394. doi:10.4088/JCP.tk16043ah5c

2. Etkin A, Patenaude B, Song YJ, et al. A cognitive-emotional biomarker for predicting remission with antidepressant medications: a report from the iSPOT-D trial. Neuropsychopharmacology. 2015;40(6):13321342. doi:10.1038/npp.2014.333

3. Fossati P, Ergis AM, Allilaire JF. Executive functioning in unipolar depression: a review. Encephale. 2002;28(2):97-107.

4. Ishak WW, Greenberg JM, Cohen RM. Predicting relapse in major depressive disorder using patient-reported outcomes of depressive symptom severity, functioning, and quality of life in the Individual Burden of Illness Index for Depression (IBI-D). J Affect Disord. 2013;151(1):59-65. doi:10.1016/j.jad.2013.05.048 
5. Serafini G, Pompili M, Belvederi Murri M, et al. The effects of repetitive transcranial magnetic stimulation on cognitive performance in treatment-resistant depression. A Systematic Review. Neuropsychobiology. 2015;71(3):125-139. doi:10.1159/000381351

6. Boes AD, Kelly MS, Trapp NT, Stern AP, Press DZ, Pascual-Leone A. Noninvasive brain stimulation: challenges and opportunities for a new clinical specialty. J Neuropsychiatry Clin Neurosci. 2018;30 (3):173-179. doi:10.1176/appi.neuropsych.17110262

7. Neville IS, Hayashi CY, El Hajj SA, Zaninotto AL, Sabino JP, Sousa LM Jr. Repetitive transcranial magnetic stimulation (rTMS) for the cognitive rehabilitation of traumatic brain injury (TBI) victims: study protocol for a randomized controlled trial. Trials. 2015;16:440. doi:10.1186/s13063-015-0944-2

8. Hayasaka S, Nakamura M, Noda Y, et al. Lateralized hippocampal volume increase following high-frequency left prefrontal repetitive transcranial magnetic stimulation in patients with major depression. Psychiatry Clin Neurosci. 2017;71(11):747-758. doi:10.1111/pcn.20 17.71.issue-11

9. Nilakantan AS, Mesulam MM, Weintraub S, Karp EL, VanHaerents S, Voss JL. Network-targeted stimulation engages neurobehavioral hallmarks of age-related memory decline. Neurology. 2019;92(20): e2349-e2354. doi:10.1212/WNL.0000000000007502

10. Shinba T, Kariya N, Matsuda S. Increase of frontal cerebral blood volume during transcranial magnetic stimulation in depression is related to treatment effectiveness: A pilot study with near-infrared spectroscopy. Psychiatry Clin Neurosci. 2018;72(8):602-610. doi:10. 1111/pcn.2018.72.issue-8

11. Bae JN, MacFall JR, Krishnan KRR, Payne ME, Steffens DC, Taylor WD. Dorsolateral prefrontal cortex and anterior cingulate cortex white matter alterations in late-life depression. Biol Psychiatry. 2006;60:1356-1363. doi:10.1016/j.biopsych.2006.03.052

12. Li CX, Sun XL, Zou K, et al. Voxel based analysis of DTI in depression patients. Int J MRI. 2007;1:43-48.

13. Lim KO, Helpen JA. Neuropsychiatric applications of DTI: a review. NMR Biomed. 2002;15:587-593. doi:10.1002/nbm.789

14. Liu X, Wang YZ, Liu HH, Liu ZN, Zhou WB. Diffusion tensor imaging and resting state functional magnetic resonance imaging on young patients with major depressive disorder. Zhong Nan Da Xue Xue Bao Yi Xue Ban. 2010;35(1):25-31. doi:10.3969/j.issn.16727347. 2010.01.004

15. Yang Q, Huang XB, Hong N, Yu X. White matter microstructural abnormalities in late-life depression. Int Psychogeriatr. 2007;19 (4):757-766. doi:10.1017/S1041610207004875

16. Scheinost D, Holmes SE, DellaGioia N, et al. Multimodal investigation of network level effects using intrinsic functional connectivity, anatomical covariance, and structure-to-function correlations in unmedicated major depressive disorder. Neuropsychopharmacology. 2018;43(5):1119-1127. doi:10.1038/npp.2017.229

17. Kozel FA, Johnson KA, Nahas Z, et al. Fractional anisotropy changes after several weeks of daily left high-frequency repetitive transcranial magnetic stimulation of the prefrontal cortex to treat major depression. J ECT. 2011;27(1):5-10. doi:10.1097/YCT.0b013e3181e6317d

18. Peng $\mathrm{H}$, Zheng $\mathrm{H}$, Li L, et al. High-frequency rTMS treatment increases white matter FA in the left middle frontal gyrus in young patients with treatment-resistant depression. J Affect Disord. 2012;136(3):249-257. doi:10.1016/j.jad.2011.12.006
19. Beck AT, Beamesderfer A. Assessment of depression: the depression inventory. Mod Probl Pharmacopsychiatry. 1974;7(0):151-169.

20. Pan S, Liu ZW, Shi S, et al. Hamilton rating scale for depression-24 (HAM-D24) as a novel predictor for diabetic microvascular complications in type 2 diabetes mellitus patients. Psychiatry Res. 2017;258:177-183. doi:10.1016/j.psychres.2017.07.050

21. Avery D, Holtzheimer P, Fawaz W, et al. Repetitive transcranial magnetic stimulation (rTMS) is clinically effective in treatment-resistant major depression. Biol Psychiatry. 2004;55:718.

22. Fitzgerald PB. Repetitive transcranial magnetic stimulation treatment for depression: lots of promise but still lots of questions. Brain Stimul. 2009;2(4):185-187. doi:10.1016/j.brs.2009.08.005

23. Fitzgerald PB, Hoy K, McQueen S, et al. A randomized trial of rTMS targeted with MRI based neuro-navigation in treatment-resistant depression. Neuropsychopharmacology. 2009;34(5):1255-1262. doi:10.1038/ npp.2008.233

24. Gelenberg AJ, Freeman MP, Markowitz JC, et al. Practice Guideline for the Treatment of Patients with Major Depressive Disorder. 3rd ed. Arlington, VA: American Psychiatric Association; 2010.

25. Guse B, Falkai P, Wobrock T. Cognitive effects of high-frequency repetitive transcranial magnetic stimulation: a systematic review. $J$ Neural Transm (Vienna). 2010;117(1):105-122. doi:10.1007/s00702009-0333-7

26. Fitzgerald PB, Hoy K, Daskalakis ZJ, Kulkarni J. A randomized trial of the anti-depressant effects of low- and high-frequency transcranial magnetic stimulation in treatment-resistant depression. Depress Anxiety. 2009;26(3):229-234. doi:10.1002/da.v26:3

27. Boggio PS, Fregni F, Bermpohl F, et al. Effect of repetitive TMS and fluoxetine on cognitive function in patients with Parkinson's disease and concurrent depression. Mov Disord. 2005;20(9):1178-1184. doi:10.1002/(ISSN)1531-8257

28. Arnsten AF, Rubia K. Neurobiological circuits regulating attention, cognitive control, motivation, and emotion: disruptions in neurodevelopmental psychiatric disorders. $J$ Am Acad Child Adolesc Psychiatry. 2012;51(4):356-367. doi:10.1016/j.jaac.2012. 01.008

29. Pallanti S, Di Rollo A, Antonini S, Cauli G, Hollander E, Quercioli L. Low-frequency rTMS over right dorsolateral prefrontal cortex in the treatment of resistant depression: cognitive improvement is independent from clinical response, resting motor threshold is related to clinical response. Neuropsychobiology. 2012;65(4):227-235. doi:10. $1159 / 000336999$

30. Alves GS, Karakaya T, Fußer F, et al. Association of microstructural white matter abnormalities with cognitive dysfunction in geriatric patients with major depression. Psychiatry Res. 2012;203(2-3):194200. doi:10.1016/j.pscychresns.2011.12.006

31. Rizk MM, Rubin-Falcone H, Keilp J, et al. White matter correlates of impaired attention control in major depressive disorder and healthy volunteers. J Affect Disord. 2017;222:103-111. doi:10.1016/j.jad.20 17.06.066

32. Stämpfli P, Sommer S, Manoliu A, et al. Subtle white matter alterations in schizophrenia identified with a new measure of fiber density. Sci Rep. 2019;9(1):4636. doi:10.1038/s41598-019-40 070-2 


\section{Publish your work in this journal}

Neuropsychiatric Disease and Treatment is an international, peerreviewed journal of clinical therapeutics and pharmacology focusing on concise rapid reporting of clinical or pre-clinical studies on a range of neuropsychiatric and neurological disorders. This journal is indexed on PubMed Central, the 'PsycINFO' database and CAS, and is the official journal of The International Neuropsychiatric Association (INA). The manuscript management system is completely online and includes a very quick and fair peer-review system, which is all easy to use. Visit http://www.dovepress.com/testimonials.php to read real quotes from published authors.

Submit your manuscript here: https://www.dovepress.com/neuropsychiatric-disease-and-treatment-journal 